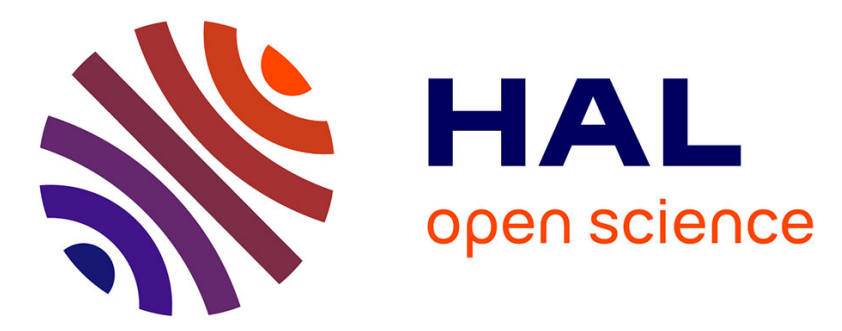

\title{
Two- and Three-Dimensional Multinuclear Stray-Field Imaging of Rotating Samples with Magic-Angle Spinning (STRAFI-MAS): From Bio to Inorganic Materials
}

\author{
Alan Wong, Dimitris Sakellariou
}

\section{- To cite this version:}

Alan Wong, Dimitris Sakellariou. Two- and Three-Dimensional Multinuclear Stray-Field Imaging of Rotating Samples with Magic-Angle Spinning (STRAFI-MAS): From Bio to Inorganic Materials. Journal of Magnetic Resonance Imaging, 2010, 32, pp.418-423. 10.1002/jmri.22242 . cea-00854047

\section{HAL Id: cea-00854047 \\ https://hal-cea.archives-ouvertes.fr/cea-00854047}

Submitted on 29 Jun 2020

HAL is a multi-disciplinary open access archive for the deposit and dissemination of scientific research documents, whether they are published or not. The documents may come from teaching and research institutions in France or abroad, or from public or private research centers.
L'archive ouverte pluridisciplinaire $\mathbf{H A L}$, est destinée au dépôt et à la diffusion de documents scientifiques de niveau recherche, publiés ou non, émanant des établissements d'enseignement et de recherche français ou étrangers, des laboratoires publics ou privés. 


\title{
Two- and Three-Dimensional Multinuclear Stray-Field Imaging of Rotating Samples with Magic-Angle Spinning (STRAFI-MAS): From Bio to Inorganic Materials
}

\author{
Alan Wong, $\mathrm{PhD}$ and Dimitris Sakellariou, $\mathrm{PhD}^{*}$
}

Purpose: To revisit and illustrate the potential of a simple and effective multidimensional stray-field imaging technique with magic-angle spinning, known as STRAFI-MAS.

Materials and Methods: STRAFI-MAS images are acquired with a standard NMR magnet and a traditional magic-angle sample spinning (MAS) probe. The stray-field gradients are achieved by placing the MAS probe, along the $z$-direction, at a distance from the center of the magnet. No pulsed-field gradients are applied. The multidimensional spatial encoding is carried out by synchronizing the radiofrequency pulses with the sample MAS rotation.

Results: Two-dimensional (2D) and 3D multinuclear images of various phantoms, including a tibia bone and silicon carbide, are recorded. Images of inorganic solids containing quadrupolar nuclei, ${ }^{23} \mathrm{Na}$ and ${ }^{27} \mathrm{Al}$, are also explored for the first time by STRAFI-MAS.

Conclusion: We have demonstrated that STRAFI-MAS is a simple and user-friendly technique for multidimensional imaging without the need of imaging equipment. With the current advancements in NMR and MRI methodologies, STRAFI-MAS is expected to be further developed and improved. We anticipate that STRAFI-MAS can spark a wide spectrum of interest, from material to bio science, where can benefit from high-resolution images.

Key Words: stray-field imaging; magic-angle rotating sample; multidimensional imaging; multinuclear imaging; large field gradient

J. Magn. Reson. Imaging 2010;32:418-423.

(C) 2010 Wiley-Liss, Inc.

UMR 3299 CEA Saclay, DSM/IRAMIS/CNRS-SIS2M/LSDRM

F-91191, Gif-sur-Yvette Cedex, France.

Contract grant sponsor: European Research Council under the European Community's Seventh Framework Programme; Contract grant number: FP7/2007-2013; Contract grant sponsor: ERC; Contract grant number: 205119.

*Address reprint requests to: D.S., CEA Saclay, DSM/IRAMIS/ SIS2M/LSDRM, F-91191, Gif-sur-Yvette Cedex, France.

E-mail: dimitrios.sakellariou@cea.fr

Received February 8, 2010; Accepted April 29, 2010.

DOI $10.1002 /$ jmri.22242

Published online in Wiley InterScience (www.interscience.wiley.com).
MRI IS AN IMAGING technique used primarily in medicine to produce high quality images for medical analysis. The technique is based on the principles of nuclear MR (NMR), a spectroscopy used by scientists to obtain microscopic chemical and physical information of liquid and solid phase materials. MRI was first demonstrated by a back reconstruction projection of ${ }^{1} \mathrm{H}$ NMR frequency in the presence of a magnetic field gradient $(1,2)$. This is, in fact, still the fundamental basis for today's MRI experiments. Field gradients along the $x, y$, and $z$ direction are necessary for encoding multidimensional $k$-space (raw image space) of a 3D sample-frame. Generally, the pulsed gradient strengths of no greater than $3 \mathrm{~T} / \mathrm{m}$ are used in most clinical and research facilities. There is a constant strive to apply higher gradients because the spatial resolution is directly dependent to the applied field gradient: the stronger the gradient, the higher the resolution. Samoilenko et al (3) was first to propose the use of a large stray-field gradient, up to $100 \mathrm{~T} / \mathrm{m}$, from the fringe field of a superconducting NMR magnet. However, stray-field imaging (STRAFI) is a $1 \mathrm{D}$ technique in nature, due to the fact that it involves a single directional gradient along the $\mathrm{z}$-axis of the laboratory frame. To overcome this handicap, there are generally two approaches toward multidimensional STRAFI. The first is by adding external pulsed-field gradients (along the $x$ and $y$ direction) for multidimensional $k$-space encoding (4); however, this would result in an uneven spatial resolution, high along the $z$ direction and low along the $x$ and $y$. The second approach is by mechanically reorienting the sample with respect to a single-directional fixed gradient (5), in such that the $k$-space encoding can be carried by a time consuming back reconstruction projection. In both approaches, specialized equipments are required and are not easily accessible.

High spatial resolution in solid samples requires additional line-narrowing techniques. For example, the first-order anisotropic interactions, such as chemical shift, dipolar coupling and magnetic susceptibility, have an angular dependence proportional to $\left(3 \cos ^{2} \Theta-1\right)$, where $\Theta$ is the angle with respect to the external magnet field $B_{o}$. These can be readily 
averaged by rotating the sample rapidly at $54.74^{\circ}$ about $B_{o}$. This line-narrowing technique is called magic-angle sample spinning (MAS) $(6,7)$, and is now a routine experiment in NMR spectroscopy for solid materials. The concept of MAS imaging have been proposed by Wind and Yannoni (8). But the first MAS imaging experiment was implemented by Cory et al $(9,10)$, where the gradient coils were built so that the gradients rotate synchronously with the MAS rotor, resulting in gradient components fixed with the sample body frame. An alternative to synchronize the gradients with the MAS rotor (i.e., the sample body frame) is by simulating the effective rotating gradients using external gradient pulses along the $x, y$, and $z$ laboratory frame. Pampel (11) has demonstrated the latter approach by inserting a standard 4-mm highresolution MAS probe into a standard pulsed-field gradient system (Bruker Micro2.5). Although the above two MAS imaging techniques promise access to high resolution imaging, they both require technically demanding hardware.

In 2005, Baltisberger et al (12) have proposed an ingenious approach for acquiring multidimensional images by combining the stray-field gradient and the line-narrowing MAS technique, where MAS is also used as a tool for sample reorientation. This technique is called STRAFI-MAS. Figure 1A illustrates the principle of STRAFI-MAS, as the sample under a continuous rotation $\left(v_{\mathrm{R}}\right)$ at the magic-angle $\left(54.74^{\circ}\right)$ about $B_{o}$, the body-frame axes $(x, y$, and $z)$ rotates and changes its orientations successively every third $\left(\mathrm{T}_{\mathrm{r}} / 3\right.$ $=120^{\circ}$ ) of a rotation. In other words, after a $120^{\circ}$ rotation of the sample holder (known as the "rotor") at the magic-angle, the $z$-body axis becomes $x$, and $x$ becomes $y$, and $y$ becomes $z$. Thereby, all three bodyfame axes have successive aligned with the fixed stray-field $z$-gradient. As a result, the spin magnetization density can be encoded at each body-axis during the three periods, $t_{1}, t_{2}$, and $t_{3}$. The encoding can be carried by a modified magic-angle turning (MAT) pulse sequence (13). A 3D experiment (Fig. 1B) begins with two $90^{\circ}$ pulses which are centered at every one-third of the rotor period, creating a balanced effective gradient orientation during the periods, $t_{1}, t_{2}$, and $t_{3}$. The two pulses excite and store the evolved magnetization, at each of the three body orientations with respect to the fixed gradient for incremented times $\Delta t_{1}, \Delta t_{2}$, and $\Delta t_{3}$, by simply tipping (first $90^{\circ}$ ) the magnetization to the transverse plane, and projecting (second $90^{\circ}$ ) back to the longitudinal $z$-axis of laboratory frame at every one-third rotor period. The last $180^{\circ}$ pulse is to eliminate image distortions, in the $t_{3}$ period, from the probe/receiver dead-time. In this experiment, the spatial $k$-space encoding is done by frequency encoding with a single fixed stray-field gradient along the $z^{-}$ axis. Similarly, a 2D experiment can be performed by encoding the frequency during two of the three sample orientations. A 2D $k$-space encoding scheme is illustrated in Figure 1C. Additional CPMG (Carr-PurcellMeiboom-Gill) (14) train pulses could be applied as an option for signal enhancement. The spatial resolution and/or the sample size is limited by the excitation bandwidth generates from the radiofrequency (rf)

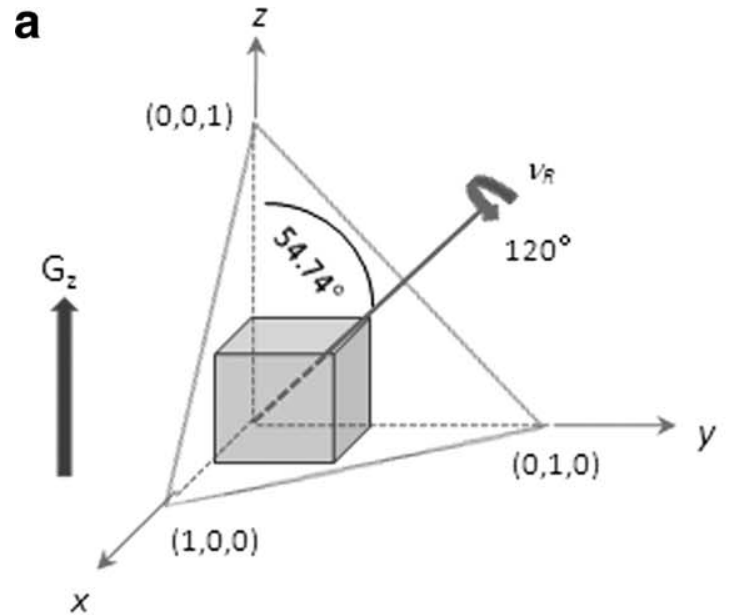

b 30 projection imaging

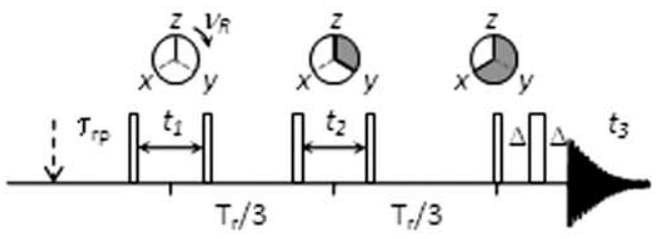

20 projection imaging

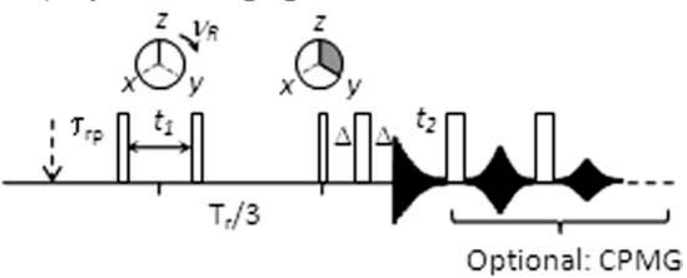

C

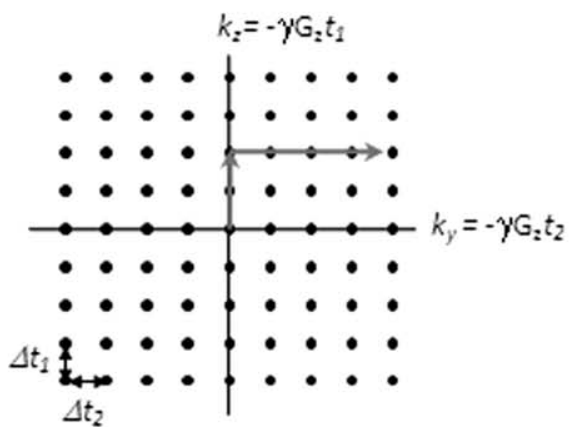

Figure 1. A: Diagram showing the sample body-fame axes, $x$, $y$, and $z$, undergoing a change of its orientation after a successive $120^{\circ}$ rotation along the magic-angle axis: $z \rightarrow y \rightarrow x$. B: STRAFI-MAS pulse experiments for encoding the $k$-space along the $x, y$, and $z$ body-axes to give raise to $2 \mathrm{D}$ and 3D spin density images. The coherence pathways of the experiment were selected as described in Baltisberger et al (12). $T_{r}$ is one rotor period of a MAS rotation. The inserted circles indicate the sample rotational phase. $\tau_{\mathrm{rp}}$ is a rotor (i.e., sample) projection period for setting the rotor projection angle $\Theta_{r p}$ of the image: $\left(1 / v_{R}\right) \times\left(\Theta_{r p} / 360^{\circ}\right)$, where $v_{R}$ is a MAS frequency. C: The $2 \mathrm{D} k$ space sampling scheme, where $\Delta t$ is the dwell time in $t_{1}$ and $t_{2}$.

power of a probehead. However, with the advancements in NMR technology, high rf-power MAS probe is readily available. Baltisberger et al (12) have demonstrated the experiment and presented $2 \mathrm{D}{ }^{1} \mathrm{H}$ images. 
To the best of our knowledge, there are no further developments and applications of STRAFI-MAS have been reported. Here, we revisit the STRAFI-MAS imaging technique with $2 \mathrm{D}$ and $3 \mathrm{D}$ image acquisitions, and explore with different spin-1/2 and spin $>1 / 2$ nuclei to illustrate its potential application to a wide range of materials.

\section{MATERIALS AND METHODS}

The STRAFI-MAS images of water phantoms and a natural abundance silicon carbide ( $\mathrm{SiC}$, purchased from Aldrich, France) were carried out on a $11.75 \mathrm{~T}$ widebore $(89 \mathrm{~mm})$ Bruker 500 UltraShield $^{\mathrm{TM}}$ magnet with a Avance III 500 spectrometer, and a standard Bruker $7 \mathrm{~mm}$ HX-CPMAS probe. The STRAFI-MAS images of a tibia bone and a $\mathrm{Na}_{2} \mathrm{SiO}_{3} / \mathrm{Al}(\mathrm{OH})_{3}$ (Aldrich, France) mixed phantom were performed on a 7.05T widebore $(89 \mathrm{~mm})$ Oxford magnet with a Avance 300 spectrometer, and a Bruker $4 \mathrm{~mm}$ HXY-CPMAS probe. The field gradients $(0.05-1.0 \mathrm{~T} / \mathrm{m})$ used in this study were achieved by simply positioning the MAS probe at an offset, along the bore of a NMR magnet, from its standard position (sweep-spot of the magnet). The gradient strengths were carefully measured from the ${ }^{1} \mathrm{H}$ linewidth of a known dimension water phantom. It should be pointed out that the gradients applied here are comparable to those offered from a standard commercial pulsed-field gradient system, up to $3 \mathrm{~T} / \mathrm{m}$. The probe's magic-angle, $54.74^{\circ}$, was carefully calibrated with ${ }^{89} \mathrm{Br}$ NMR of $\mathrm{KBr}$. The MAS frequency was manually adjusted using a standard Bruker pneumatic controller. Spinning frequencies of less than $200 \mathrm{~Hz}$ with stability less than $\pm 1 \mathrm{~Hz}$ were achieved with a custom-made turbine-less Kel-F rotor cap. All multidimensional images were recorded with States phase cycling (15) and processed with an exponential apodization on the $t_{1}$ and $t_{2}$ time-domain data to improve the signal-to-noise ratio. Zero-filling was also applied to improve the pixel definition quality. Further experimental and processing details are provided in the figure captions.

\section{RESULTS AND DISCUSSION ${ }^{1} \mathrm{H}$ Images of Water Phantoms}

Figure 2A shows a $2 \mathrm{D}{ }^{1} \mathrm{H}$ image of a Kel-F insert having two chambers filled with water inside a $7-\mathrm{mm}$ MAS rotor, with a resolution about $185 \mu \mathrm{m} \times 730 \mu \mathrm{m}$. The tilted image (pointing at the magic-angle) can be readily sheared by a simple $2 \mathrm{D}$ rotational matrix to a favorable representation. Although the image is acquired with a relatively low stray-field $\mathrm{z}$-gradient $(<0.1 \mathrm{~T} / \mathrm{m})$, it shows the physical features of the phantom: two water chambers with an unsmooth surface all around the wall. The $2 \mathrm{D}$ image is carried out under a slow continuous magic-angle rotation, having a frequency of $105 \mathrm{~Hz}$ with stability of less than \pm 1 $\mathrm{Hz}$. The slow and stable rotation reduces the image distortion arises from the change in the gradient orientation during $t_{1}$ and $t_{2}$ (12). Moreover, short echo period $(\Delta=5 \mu \mathrm{s})$ is used to minimize the distortion

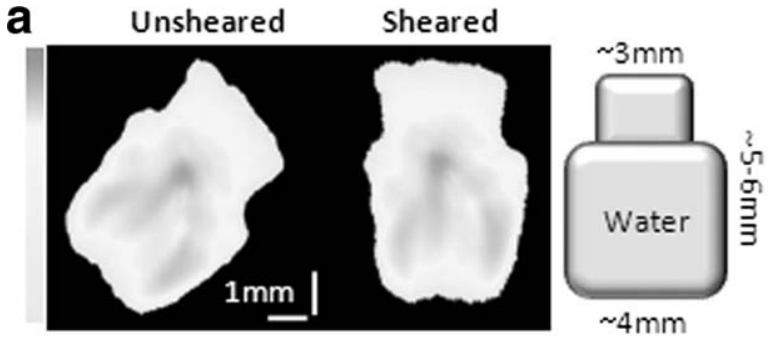

b
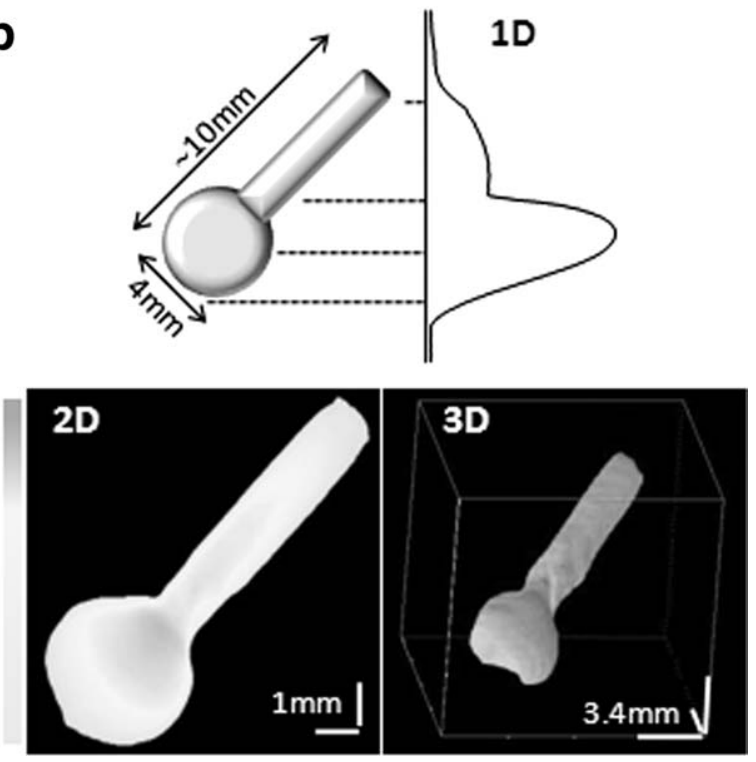

Figure 2. A: Unsheared and sheared ${ }^{1} \mathrm{H} 2 \mathrm{D}$ image of a water phantom of two-chamber 7-mm Kel-F insert. The phantom is displayed on the right. Experimental details: probe offset 5.8 $\mathrm{cm} ;{ }^{1} \mathrm{H}$ frequency at $499.12 \mathrm{MHz} ; \mathrm{z}$-gradient $\sim 0.05 \mathrm{~T} / \mathrm{m} ; 105$ $\pm 1 \mathrm{~Hz}$ MAS; $2.5 \mu \mathrm{s} 90^{\circ}$ pulse width ( ${ }^{1} \mathrm{H}$-rf of $100 \mathrm{kHz}$ ); $0 \mu \mathrm{s}$ $\tau_{\text {rp }} ; 5 \mu \mathrm{s} \Delta$; $0.25 \mathrm{~s}$ recycle delay; 8 scans; 512 and 128 real data points were collected for a $200,000 \mathrm{~Hz}$ spectral width in $F_{2}$ and $F_{1}$, respectively. The total acquisition time is $9 \mathrm{~min}$. The image was processed with an exponential apodization of $200 \mathrm{~Hz}$ in $t_{2}$ and $t_{1} \cdot t_{2}$ and $t_{1}$ data were zero-filled to 2048 points to increase the pixel resolution; however, the actual image resolution ca. $185 \mu \mathrm{m} \times 730 \mu \mathrm{m}$ is unaffected. B: Water phantom of a 4-mm round bottle flask inside a $7-\mathrm{mm}$ MAS rotor. Experimental details: probe offset $7.9 \mathrm{~cm} ;{ }^{1} \mathrm{H}$ frequency at $498.88 \mathrm{MHz} ; z$-gradient $\sim 0.62 \mathrm{~T} / \mathrm{m} ; 111 \pm 1 \mathrm{~Hz}$ MAS; $2.5 \mu \mathrm{s} 90^{\circ}$ pulse width $\left({ }^{1} \mathrm{H}-\mathrm{rf}\right.$ of $\left.100 \mathrm{kHz}\right)$; [for $1 \mathrm{D}$ projection] $0 \mathrm{~Hz}$ MAS (i.e., static sample); acquired with a fullecho; $5 \mathrm{~s}$ recycle delay; 16 scans; [for $2 \mathrm{D}$ projection] $0.5 \mathrm{~s}$ recycle delay; 32 scans; $0 \mu \mathrm{s} \tau_{\mathrm{rp}} ; 5 \mu \mathrm{s} \Delta$; 1024 and 50 real data points were collected for a $500,000 \mathrm{~Hz}$ spectral width in $\mathrm{F}_{2}$ and $\mathrm{F}_{1}$, respectively. Acquisition time is $30 \mathrm{~min}$. The image was processed with an exponential apodization of 500 $\mathrm{Hz}$ in $t_{2}$ and $t_{1}$, and zero-filled to 2048 and 512 points, respectively. The image resolution is about $19 \mu \mathrm{m} \times 380 \mu \mathrm{m}$; [for $3 \mathrm{D}$ projection] $0.7 \mathrm{~s}$ recycle delay; 32 scans; $5 \mu \mathrm{s} \Delta$; 1024, 26 and 50 real data points were collected for a $500,000 \mathrm{~Hz}$ spectral width in $\mathrm{F}_{3}, \mathrm{~F}_{2}$, and $\mathrm{F}_{1}$, respectively. The acquisition time is $32 \mathrm{hr}$. The image was processed with an exponential apodization of $1000 \mathrm{~Hz}$ in $t_{3}, t_{2}$, and $t_{1}$, and zero-filled to 2048, 64 and 128 points, respectively. The image resolution is ca. $19 \mu \mathrm{m} \times 743 \mu \mathrm{m} \times 379 \mu \mathrm{m}$.

arising from the slight difference in the gradient orientation during each $\Delta$ period (12). Thus, slow and stable MAS conditions with short $\Delta$ minimize the 


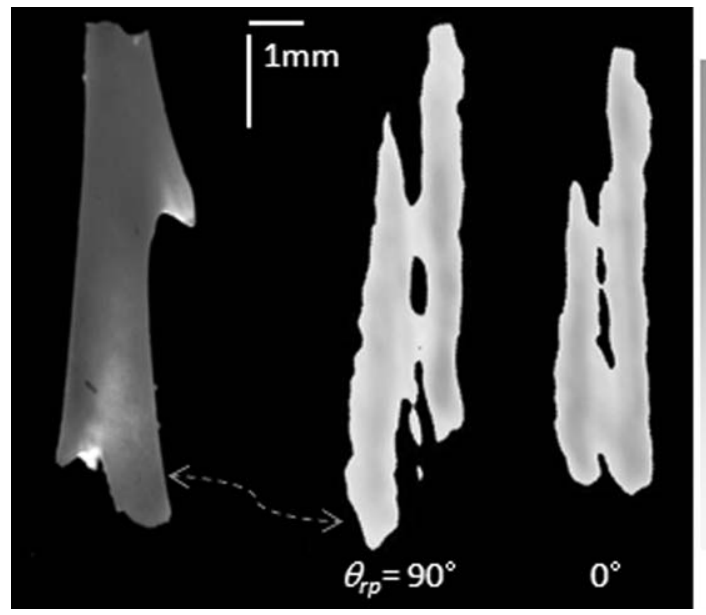

Figure 3. A photograph of a hollow tibia bone (left) and its sheared ${ }^{1} \mathrm{H}$ images with two different rotor projection angles $\Theta_{r p}, 0^{\circ}$ and $90^{\circ}$ (right). Experimental details: probe offset 9.7 $\mathrm{cm} ;{ }^{1} \mathrm{H}$ frequency at $298.12 \mathrm{MHz} ; \mathrm{z}$-gradient $\sim 0.9 \mathrm{~T} / \mathrm{m} ; 1050$ $\pm 5 \mathrm{~Hz}$ MAS; $2 \mu \mathrm{s} 90^{\circ}$ pulse width $\left({ }^{1} \mathrm{H}-\mathrm{rf}\right.$ of $\left.125 \mathrm{kHz}\right) ; 0$ and $238 \mu \mathrm{s} \tau_{\mathrm{rp}}$, which correspond to $\Theta_{\mathrm{rp}} 0^{\circ}$ and $90^{\circ}$, respectively; $5 \mu \mathrm{s} \Delta ; 1 \mathrm{~s}$ recycle delay; 64 scans, 512 and 64 real data points were collected for a $1,000,000 \mathrm{~Hz}$ spectral width in F2 and $\mathrm{Fl}$. The acquisition time is $2.3 \mathrm{hr}$. The image was processed with an exponential apodization of $3000 \mathrm{~Hz}$ in $t_{2}$ and $t_{1}$, and zero-filled to 1024 and 512 points, respectively. The image resolution is ca. $51 \mu \mathrm{m} \times 408 \mu \mathrm{m}$.

imperfection of gradient orientation, and provide good quality images. Similarly, Figure 2B shows 1D, 2D, and 3D images of water inside a $4-\mathrm{mm}$ round-bottle flask. The images were acquired with a gradient of $\sim 0.62 \mathrm{~T} / \mathrm{m}$. The resultant resolutions are estimated to be $19 \mu \mathrm{m} \times 379 \mu \mathrm{m}$ for $2 \mathrm{D}$, and $19 \mu \mathrm{m} \times 743 \mu \mathrm{m}$ $\times 379 \mu \mathrm{m}$ for 3D. The images are acquired under a slow MAS (spinning frequency of $111 \mathrm{~Hz}$ ) with a short $\Delta$ period $(5 \mu \mathrm{s})$ to eliminate distortions, and are in good agreement with the water phantom. Note that the 3D image appears to be tilted, and is slightly distorted around the round bottle region. The latter is contributed from the fact that the signal is truncated during the $t_{2}$ period, and results in a poor pixel resolution $(743 \mu \mathrm{m})$ along the $t_{2}$ dimension. An improved image could be acquired with longer acquisition time. Nevertheless, the 3D image reveals the round bottle feature quite well, and it represents the first threedimensional image acquired by STRAFI-MAS.

\section{${ }^{1}$ H Image of a Tibia Bone}

The 2D STRAFI-MAS images of a small hollow tibia bone $(\sim 6 \mathrm{~mm} \times \sim 1.5 \mathrm{~mm})$ are carried out at $7.05 \mathrm{~T}$ with a stray-field gradient of $\sim 0.9 \mathrm{~T} / \mathrm{m}$, and are shown in Figure 3. The resolution is approximately 51 $\mu \mathrm{m} \times 408 \mu \mathrm{m}$. The probe was positioned $9.7 \mathrm{~cm}$ below the center of the magnet. Although the image's feature does not agree well with the tibia bone shown in the photograph on the left, it does display the high ${ }^{1} \mathrm{H}$ density regions at the two long edges, and the low density at the center (hollow) region. Moreover, the two images with different rotor (i.e., sample) projection angles $\left(\Theta_{\mathrm{rp}}=360^{\circ} \times v_{R} \times \tau_{\mathrm{rp}}\right.$, where $\nu_{R}$ is a MAS frequency and $\tau_{\mathrm{rp}}$ is the rotor projection period used in the experiment), $0^{\circ}$ and $90^{\circ}$, do correspond modestly with the view projection of the bone. For example, the image with a $90^{\circ}$ rotor projection corresponds to a mirror reflection of the photograph; whereas, the image with $0^{\circ}$ rotor projection corresponds to a $90^{\circ}$ turn of the photographic picture. The visible distortions in the images arise from the fact that the experiments were carried out in an unstable MAS rotation, $1050 \mathrm{~Hz}$ with a constant fluctuation of $\pm 5 \mathrm{~Hz}$. A better image quality could be obtained with a slower and a more stable MAS rotation. This could be achieved by using a larger MAS rotor with a turbine-less cap. It is interesting to note that Tritt-Goc et al (16) have acquired high spatial $3 \mathrm{D}$ resolution images $(60 \times 60$ $\times 60 \mu \mathrm{m}$ ) of a human trabecular bone at 7T to investigate a bone disease called osteoporosis. In the study, a field gradient of $1 \mathrm{~T} / \mathrm{m}$ was used along the $x, y$, and $z$ direction, which is comparable to what we applied here for the tibia bone.

\section{${ }^{29}$ Si Image of Silicon Carbide}

Silicon is a widely used element in many applications, ranging from high endurance materials (i.e., automobile components, bearings, and abrasives) to electronic and nuclear energy applications (i.e., radioactive storage components, emitting diodes, detectors, and fuel). Thereby ${ }^{29} \mathrm{Si}$ MAS experiments are vastly applied to study the atomic structure around the silicon sites (17). Figure 4 shows a ${ }^{29} \mathrm{Si}$ image of an industrial importance silicon material, $\mathrm{SiC}$ powder, packed without any effort to generate a featured object, at the center region of a $7-\mathrm{mm}$ rotor. It was acquired with a gradient of $\sim 0.45 \mathrm{~T} / \mathrm{m}$, and a stable MAS rotation frequency of $1800 \mathrm{~Hz}$. The image resolution is approximately $56 \mu \mathrm{m} \times 521 \mu \mathrm{m}$. The image dimensions correspond well with those of the phantom. The distortion of nonparallel edges is attributed to a combination of the fast MAS and the inherently low sensitive ${ }^{29} \mathrm{Si}$ nucleus. The low ${ }^{29} \mathrm{Si}$ natural

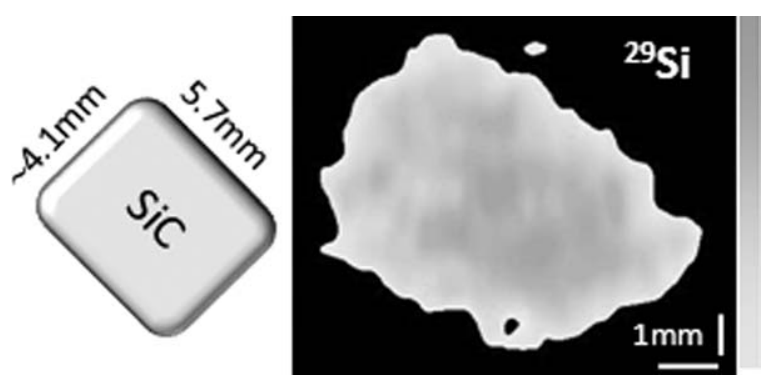

Figure 4. ${ }^{29} \mathrm{Si}$ image of natural abundance $\mathrm{SiC}$ powder tightly packed at the center of a $7-\mathrm{mm}$ rotor. Experimental details: probe offset $7 \mathrm{~cm} ;{ }^{29} \mathrm{Si}$ frequency at $99.16 \mathrm{MHz} ; \mathrm{z}$ gradient $\sim 0.45 \mathrm{~T} / \mathrm{m} ; 1800 \pm 1 \mathrm{~Hz}$ MAS; $3.4 \mu \mathrm{s} 90^{\circ}$ pulse width $\left({ }^{29} \mathrm{Si}-\mathrm{rf}\right.$ of $\left.74 \mathrm{kHz}\right) ; 0 \mu \mathrm{s} \tau_{\mathrm{rp}} ; 5 \mu \mathrm{s} \Delta ; 330 \mathrm{~s}$ recycle delay; 32 scans, 150 and 16 real data points were collected for a $50000 \mathrm{~Hz}$ spectral width in $\mathrm{F}_{2}$ and $\mathrm{F}_{1}$. The acquisition time is $39 \mathrm{hr}$. The image was processed with an exponential apodization of $1000 \mathrm{~Hz}$ in $t_{2}$ and $t_{1}$, and zero-filled to 2048 and 512 points, respectively. The image resolution is ca. 56 $\mu \mathrm{m} \times 521 \mu \mathrm{m}$. 
abundance $(4.7 \%)$, and the long longitudinal relaxation time $T_{2}(1.9 \mathrm{~min})$ for ${ }^{29} \mathrm{SiC}$ (18) result in a very time consuming experiment. Fortunately, in both crystalline and amorphous natural abundance samples, the intrinsic transverse relaxation time $T_{2}$ of the ${ }^{29} \mathrm{Si}$ nuclei can be much longer than $T_{2} *$ rendering the possibility of observing successive Hahn echoes in a CPMG train, and enhancing the sensitivity during the acquisition $(19,20)$. Larsen and Farnan (19) has demonstrated that $1 \mathrm{D}^{29} \mathrm{Si}$ NMR signal enhancement with ${ }^{29} \mathrm{Si}$ MAS CPMG on silicon glasses. Similarly, the ${ }^{29} \mathrm{Si}$ signal efficiency of implementing CPMG into a highresolution 2D MAT experiment has also been demonstrated (20). Thereby in principle, a signal enhanced STRAFI-MAS image could be readily achieved by coupling the CPMG during the signal acquisition period, see Figure 1B. ${ }^{29} \mathrm{Si}$ STRAFI-MAS with CPMG is a direction that we plan on pursuing and demonstrate in a near future.

\section{${ }^{23} \mathrm{Na}$ And ${ }^{27} \mathrm{Al}$ Images of Inorganic Salts}

To investigate the extension of STRAFI-MAS to quadrupolar nuclei (spin $>1 / 2$ ), we chose to image with ${ }^{23} \mathrm{Na}(I=3 / 2)$ and ${ }^{27} \mathrm{Al}(I=5 / 2)$, which are abundance elements in materials, and are commonly characterized by MAS spectroscopy. Due to the additional quadrupolar interaction in the quadrupolar nuclei, it often resulted in fast spin-spin transverse relaxation and broad resonance, hindering high resolution imaging. Despite this, ${ }^{23} \mathrm{Na} \mathrm{MRI}$ is still a good diagnostic technique for localizing and quantifying the sodium concentration in materials such as foods (21), soft tissues (22), bone cartilages (23), and cements (24). Most of today's ${ }^{23} \mathrm{Na}$ imaging is done on nonrigid samples, or highly mobile sodium ions, where the quadrupolar interaction is expected to be small. For rigid samples, the second-order quadrupolar interaction can become sufficient and hampering for ${ }^{23} \mathrm{Na}$ imaging. Even under MAS, the resonance lines may show certain frequency distributions arising from the second-order anisotropic interaction yielding quadrupolar parameters: $v_{B}=\left[3 \mathrm{C}_{3} / 2 I(2 I-1)\right]\left(1+\eta^{2} / 3\right)^{0.5}$, where $\mathrm{C}_{\mathrm{B}}$ and $\eta$ are quadrupolar coupling constant and asymmetry parameter, respectively. Figure 5 shows ${ }^{23} \mathrm{Na}$ and ${ }^{27} \mathrm{Al}$ STRAFI-MAS images of a solid phantom consists of $\mathrm{Al}(\mathrm{OH})_{3}$ and $\mathrm{Na}_{2} \mathrm{SiO}_{3}$ powder layers each with $1-2 \mathrm{~mm}$ thickness. Under a fast but stable $1500 \mathrm{~Hz}$ MAS, we were able to acquire ${ }^{23} \mathrm{Na}$ and ${ }^{27} \mathrm{Al}$ images with full-echo acquisition (one rotor period for $\Delta)$ to eliminate image distortion from the imperfection of magnetization refocusing during the $t_{2}$ period. However, the distortions around the edges are mainly attributed to the second-order quadrupolar interaction. In the case, the ${ }^{27} \mathrm{Al}$ image is slightly more distorted compared to ${ }^{23} \mathrm{Na}$. This is due to the fact that $\mathrm{Al}(\mathrm{OH})_{3}$ consists of two ${ }^{27} \mathrm{Al}$ sites with different quadrupolar frequency $v_{\mathrm{O}}, 0.24$ and $0.67 \mathrm{MHz}$ (25); whereas, $\mathrm{Na}_{2} \mathrm{SiO}_{3}$ has only one ${ }^{23} \mathrm{Na}$ site with $v_{\mathrm{B}}$ of $0.79 \mathrm{MHz}$ (26). Despite the distortion, the ${ }^{23} \mathrm{Na}$ and ${ }^{27} \mathrm{Al}$ images shown in Figure 5 clearly display the individual layers containing sodium in $\mathrm{Na}_{2} \mathrm{SiO}_{3}$ and aluminum in $\mathrm{Al}(\mathrm{OH})_{3}$. In principle, a magic-angle turning

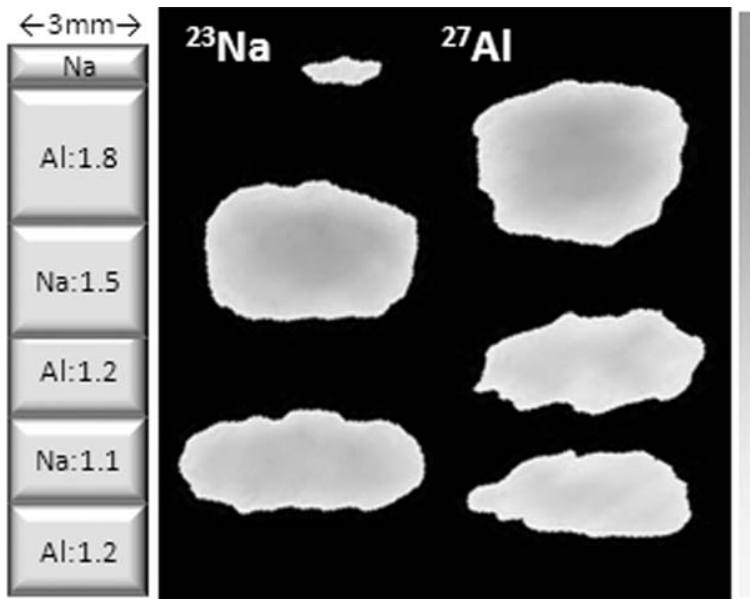

Figure 5. (Left) $\mathrm{A} \mathrm{Na} \mathrm{NiO}_{3} / \mathrm{Al}(\mathrm{OH})_{3}$ phantom with the number (in millimeters) indicating the estimated thickness of each layer. (Right) ${ }^{23} \mathrm{Na}$ and ${ }^{27} \mathrm{Al}$ STRAFI-MAS images. Experimental details: probe offset $8.6 \mathrm{~cm} ;{ }^{23} \mathrm{Na}$ and ${ }^{27} \mathrm{Al}$ frequency at 79.14 and $77.95 \mathrm{MHz}$, respectively; z-gradient $\sim 0.47 \mathrm{~T} / \mathrm{m} ; 1500 \pm 1 \mathrm{~Hz}$ MAS; [for ${ }^{23} \mathrm{Na}$ ] $1.13 \mu \mathrm{s}$ solid-90 ${ }^{\circ}$ pulse width $\left({ }^{23} \mathrm{Na}-\mathrm{rf}\right.$ of $\left.111 \mathrm{kHz}\right) ; 0 \mu \mathrm{s} \tau_{\mathrm{rp}}$; acquired with a full-echo; 3-s recycle delay; 64 scans; 512 and 46 real data points were collected for a $1,000,000 \mathrm{~Hz}$ spectral width in $\mathrm{F}_{2}$ and $\mathrm{F}_{1}$. The acquisition time is $4.8 \mathrm{hr}$. The image was processed with an exponential function of $1200 \mathrm{~Hz}$ in $t_{2}$ and $t_{1}$, and zero-filled to 4096 and 512 points, respectively; [for ${ }^{27} \mathrm{Al}$ ] $1.25 \mu \mathrm{s}$ solid-90 pulse width $\left({ }^{27} \mathrm{Al}-\mathrm{rf}\right.$ of $\left.67 \mathrm{kHz}\right) ; 0 \mu \mathrm{s} \tau_{\mathrm{rp}}$; acquired with a full-echo; 0.1 s recycle delay; 2024 scans; 512 and 28 real data pointed were collected for a 1,000,000 $\mathrm{Hz}$ spectral width in $\mathrm{F}_{2}$ and $\mathrm{F}_{1}$. The acquisition time is $3 \mathrm{hr}$. The image was processed with an exponential apodization of $1500 \mathrm{~Hz}$ in $t_{2}$ and $t_{1}$, and zero-filled to 2048 and 512 points, respectively.

experiment for quadrupolar nuclei (QMAT) (27) could be incorporated in the STRAFI-MAS experiment to minimize the distortion by suppressing the inherent MAS sidebands. Alternatively, a larger magnetic field gradient, such that it dominates the nuclear quadrupolar interaction, could be used to improve the spatial resolution and suppress the distortion from the quadrupolar interaction. Notice that very large stray-field gradients are easily accessible away from the center of any NMR magnet.

The continuous sample rotation is a main factor contributing to the image distortion in STRAFI-MAS (12). It arises from the imperfection of gradient orientation in $t_{1}, t_{2}$, and $t_{3}$ evaluation periods, and the sample vibration during the course of sample rotation. We minimized these effects by means of slow and stable MAS sample rotation, and showed good quality 2D images of water phantoms in Figure 2. Alternatively, the distortion from the sample rotation could be "completely" eliminated by using a discrete sudden $120^{\circ}$ rotation (rather than a continuous rotation, MAS), about an axis oriented at the magic-angle to $B_{o}$, between the $t_{1}, t_{2}$, and $t_{3}$ periods. This, in fact, is the principle of a magic-angle hoping (MAH) experiment (28) for obtaining high-resolution solid-state NMR spectroscopy. In principle, the STRAFI-MAS experiment could be served as a protocol for incorporating 
MAH with STRAFI as a new and improved approach for multidimensional NMR imaging.

In conclusion, this study demonstrates a potentially useful technique, STRAFI-MAS, for multidimensional and multinuclear imaging. It utilizes the easily accessible large gradient from the stray-field of a NMR magnet, and the slow sample reorientations around the magic-angle. In addition, the experiment is userfriendly and simple to set up. It only requires a standard MAS probe capable of stable slow spinning. Although at this point, STRAFI-MAS is a primitive multidimensional imaging technique, but there is plenty of room for further developments. For example, adding CPMG echo pulses would enhance signal sensitivity; and implementing $T_{1}, T_{1 \rho}$, or multiquantum filter pulses would provide contrasting images, which are an enormous advantage for MRI over other imaging techniques. With the accessible large gradient and the simplicity of the experiment, we anticipate that STRAFI-MAS is a promising imaging technique for a wide range of microscopic studies, including micro- or maybe even nano-scale imaging by adopting the recent developments of micro-sized slow MAS NMR spectroscopy $(29,30)$. One highly possible interest would be cell-imaging, where it can benefit from the large stray-field field gradient for ultra-high resolution.

\section{ACKNOWLEDGMENTS}

We thank Dr. Sabine Hediger (Lyon, France) for the helpful discussions on the STRAFI-MAS experiment, and Dr. Pedro Aguiar and Mr. Angelo Guiga (Gif-surYvette, France) for their contributions on insert fabrication. We are also grateful to Dr. Sara Laurencin Dalicieux (France) for providing the mouse tibia bone. We also thank the referees for their valuable comments.

\section{REFERENCES}

1. Lauterbur PC. Image formation by induced local interactions: examples employing nuclear magnetic resonance. Nature 1973; 242:190-191.

2. Mansfield P, Grannell PK. NMR ‘diffraction' in solids? J Phys C Solid State Phys 1973;6:L422-L426.

3. Samoilenko AA, Artemov DY, Sibeldina LA. Formation of sensitive layer in experiments on NMR subsurface imaging of solids. JETP Letters 1988;47:417-419.

4. Godward J, Ciampi E, Cifelli M, Mcdonald PJ. Multidimensional imaging using combined stray field and pulsed gradients. J Magn Reson 2002;155:92-99.

5. Samoilenko AA, Zick K. Stray field imaging of solids. Bruker Report 1990;1:40-41.

6. Andrew ER, Bradbury A, Eades RG. Nuclear magnetic resonance spectra from a crystal rotated at high speed. Nature 1958;182:1659.

7. Lowe I. Free induction decays of rotating solids. Phys Rev Lett 1959;2:285-287.

8. Wind RA, Yannoni CS. Spin imaging in solids using synchronously rotating field gradients and samples. US patent 4,301,410, 17 November 1981.
9. Cory DG, Reichwein AM, Van OS-JWM, Veeman WS. NMR images of rigid solids. Chem Phys Lett 1988;143:467-470.

10. Cory DG, Van OS-JWM, Veeman WS. NMR images of rotating solids. J Magn Reson 1988;76:543-547.

11. Pampel A, Engeike F, Gro $\beta$ D, Oerther T, Zick K. Pulse-field-gradient NMR with magic-angle spinning: diffusion studies and NMR microscopy of heterogeneous materials. Bruker Spin Report, 2006;157/158:26-30.

12. Baltisberger JH, Hediger S, Emsley L. Multi-dimensional magnetic resonance imaging in a stray magnetic field. J Magn Reson 2005;172:79-84.

13. Gan $Z$. High-resolution chemical shift and chemical shift anisotropy correlation in solids using slow magic-angle spinning. J Am Chem Soc 1992;114:8307-8309.

14. Waugh JS. Sensitivity in Fourier transforms NMR spectroscopy of slowly relaxing systems. J Mol Spectrosc 1970;35:298-305.

15. States DJ, Haberkorn RA, Ruben DJ. A two-dimensional nuclear overhauser experiment with pure absorption phase in four quadrants. J Magn Reson 1982;48:286-292.

16. Tritt-Goc J, Piślewski N, Hachulska AK, Chmielewski D, Górecki A, Kolodziejski W. Proton magnetic resonance microimaging of human trabecular bone. Solid State Nucl Magn Reson 1999;15: 91-98.

17. Farnan I, Cho H, Weber WJ. Quantification of actinide alpharadiation damage in minerals and ceramics. Nature 2007;445: 190-193.

18. Leonova E, Grins J, Shariatgorji M, Ilag LL, Edén M. Solid-state NMR investigations of Si-17 and N-15 enriched silicon nitride. Solid State Nucl Magn Reson 2009;36:11-18.

19. Larsen FH, Farnan I. ${ }^{29} \mathrm{Si}$ and ${ }^{17} \mathrm{O}$ (Q)CPMG-MAS solid-state NMR experiments as an optimum approach for half-integer nuclei having long $T_{1}$ relaxation times. Chem Phys Lett 2002;357: 403-408.

20. Sakellariou D, Jacquinot J-F, Charpentier T. 2D correlation spectra of isotropic and anisotropic ${ }^{29} \mathrm{Si}$ chemical shifts in crystalline and amorphous natural abundance materials under very slow sample rotation. Chem Phys Lett 2005;411:171-174.

21. Veliyulin E, Egelandsdal B, Marica F, Balcom BJ. Quantitative 23Na magnetic resonance imaging of model foods. J Agric Food Chem 2009;57:4091-4095.

22. Maril N, Rosen Y, Reynolds GH, Ivanishev A, Ngo L, Lenkinski RE. Sodium MRI of the human kidney at 3 Tesla. Magn Reson Med 2006;56:1229-1234.

23. Borthakur A, Mellon E, Niyogi S, Witschey W, Kneeland JB, Reddy R. Sodium and T1rho MRI for molecular and diagnostic imaging of articular cartilage. NMR Biomed 2006;19:781-821.

24. Cano FdJ, Bremner TW, McGregor RP, Balcom BJ. Magnetic resonance imaging of ${ }^{1} \mathrm{H},{ }^{23} \mathrm{Na}$, and ${ }^{35} \mathrm{Cl}$ penetration in Portland cement mortar. Cem Concr Res 2002;32:1067-1070.

25. Faucon P, Charpentier T, Bertrandie D, Nonat A, Virlet J, Petit JC. Characterization of calcium aluminate hydrates and related hydrates of cement pastes by ${ }^{27} \mathrm{Al} \mathrm{MQ-MAS} \mathrm{NMR.} \mathrm{Inorg} \mathrm{Chem}$ 1998;37:3726-3733.

26. Koller H, Engelhardt G, Kentgens A, Sauer J. ${ }^{23}$ Na NMR spectroscopy of solids: interpretation of quadrupole interaction parameters and chemical shifts. J Phys Chem 1994;98:1544-1551.

27. Nakai T, Kuwahara D. Spinning sideband summation for quadrupole MAS NMR spectra using a magic-angle turning technique. Chem Phys Lett 1996;249:205-209.

28. Bax AD, Szeverenyi NM, Maciel GE. Correlation of isotropic shifts and chemical shift anisotropies by two-dimensional Fouriertransform magic-angle hopping NMR spectroscopy. J Magn Reson 1983;52:147-152.

29. Sakellariou D, Goff GL, Jacquinot J-F. High-resolution, high-sensitivity NMR of nanolitre anisotropic samples by coil spinning. Nature 2007;447:694-697.

30. Wong A, Augiar PM, Sakellariou D. Slow magic-angle coil spinning: a high-sensitivity and high-resolution NMR strategy for microscopic biological specimens. Magn Reson Med 2010;63: 269-274. 